\title{
Analisis Strategi Pengembangan Agribisnis Semangka (Citrullus lanatus) Pada CV Tani Makmur Di Kabupaten Jombang
}

\author{
Serli Febrina Wahidiyanti \\ Magister Agribisnis Universitas Islam Kadiri \\ Email:sherly.f.wahidiyanti@gmail.com
}

\begin{abstract}
Fruits are a source of vitamins and minerals needed by the body. Apart from being a source of vitamins and minterals, watermelon is one type of fruits that have a high economic value. One company that seizes the watermelon business opportunity is CV Tani Makmur. To maintain the business of watermelon fruit, CV Tani Makmur party needs to do a strategy for the company to grow and avoid the loss. The purpose of this research is (1) An analize the development strategi of watermelon agribusiness, (2) Identify development strategi of internal and external area. This research was conducted from February to June 2017. The results of internal environmental analysis with IFE matrix shows that the business of watermelon CV Tani Makmur has a total score of 3.1234. This value is above the average value of 2.5 indicating that the development of the watermelon business CV Tani Makmur is above average, ie the company is able to utilize its strength quite well. In addition, the company can minimize its weaknesses quite well. While the results of external environmental analysis with the EFE matrix shows that the business of watermelon CV Tani Makmur has a total score of 2.3079. This value is below the average score of 2.5 indicating that in the business development of watermelon fruit, CV Tani Makmur less respond to opportunities that exist. In addition, firms are less able to avoid threats to the watermelon business. Companies can be managed with grow and build strategies. The result of the strategy with the SWOT matrix resulted in seven alternative strategies. The QSP matrix resulted in the priority of the alternative strategy in the business strategy of watermelon fruit of CV Tani Makmur with the highest STAS (Sum Total Attractivity) score is to develop the human resources performance to increase the production and the broader target market with STAS of 5.4266. This strategy is a strategy of utilizing the company's strength to overcome the weakness of the watermelon business of CV Tani Makmur.

Keywords : Strategy, Development, Internal and External Factor
\end{abstract}

\section{Pendahuluan}

Usaha agribisnis buah-buahan merupakan sumber pendapatan tunai bagi petani di pedesaan sebagai sumber pendapatan keluarga, karena di tunjang oleh potensi lahan, iklim dan sumber daya manusia yang memadai serta peluang pasar domestik dan internasional yang sangat luas. Selain sebagai komoditas unggulan, komoditas buah buahan juga berperan sebagai sumber gizi masyarakat serta sebagi penghasil tambahan devisa Negara. Semangka (Citrullus lanatus) adalah salah satu tanaman buah yang sudah memasyarakat. Semangka ini terkenal karena nyaris tak berbiji atau mempunyai biji yang sangat sedikit (Seed less), presentase berbuah lebih tinggi dibandingkan buah tanpa biji lainnya sebagaimana semangka pada umumnya. Dengan keistimewaan itu Semangka lebih diminati dan memiliki keunggulan nilai ekonomi untuk dibudidayakan.

Dikatakan oleh Pasaribu, Ali Musa (2012), Pembangunan sektor pertanian identik dengan pembanguan ekonomi secara nasional, sektor pertanian tidak identik dengan Kementerian Pertanian, namun identik dengan sistem agribisnis. Oleh karena itu sektor pertanian adalah Scope arti yang luas dimiliki oleh tiga (3) Kementerian RI, yaitu Kementerian Pertanian, Kementerian Kelautan dan Perikanan, dan Kementerian Kehutanan. Sektor Pertanian dalam Perhitungan Domestik Bruto (PDB) didukung oleh lima (5) subsektor, yaitu subsektor Tanaman Pangan dan Hortikultura, subsektor Perkebunan, subsektor Peternakan, dan subsektor Kehutanan. Sesuai dengan amanah GBHN Konstitusi Tahun 19992004 sebagai grand strategi 
pembangunan ekonomi Indonesia secara holistik, yaitu Agribisnis led development.

\section{Metode Penelitian \\ Lokasi dan Waktu Penelitian}

Lokasi penelitian ini dilakukan pada CV Tani Makmur yang terletak di Desa Balongsari, Kecamatan Megaluh, Kabupaten Jombang, Provinsi Jawa Timur. Lokasi tersebut dipilih secara sengaja (purposive) dengan pertimbangan bahwa perusahaan tersebut merupakan salah satu produsen penghasil buah semangka di Jombang.

\section{Jenis dan Sumber Data}

Data yang digunakan berasal dari data primer dan data sekunder. Data primer berasal dari wawancara dan kuesioner terhadap responden serta observasi langsung di lapangan mengenai kegiatan yang menunjang penelitian. Responden yang dimaksud merupakan pihak internal dan eksternal pada bisnis buah semangka CV Tani Makmur. Pihak internal perusahaan yaitu General Manager, yang merupakan pengambil keputusan dalam perusahaan. Responden eksternal yaitu petani mitra dan petani musiman CV Tani Makmur. Responden ini memberi gambaran mengenai hubungan kerjasama yang terjalin dan bagaimana penilaian petani terhadap perusahaan. Responden petani mitra dan petani musiman CV Tani Makmur ini berjumlah 15 orang petani mitra dan 45 orang petani musiman yang tersebar di berbagai wilayah Kabupaten Jombang. Untuk itu, pengambilan data menggunakan metode sensus, hanya bagi petani mitra dan musiman yang pada saat penelitian melakukan budidaya semangka di kabupaten Jombang. Data primer yang diperoleh digunakan untuk melakukan analisis internal dan eksternal yang merupakan dasar bagi analisis perumusan strategi.

\section{Hasil Dan Pembahasan \\ Potensi Daerah Kab. Jombang}

Kabupaten Jomabng terletak pada bagian tengah Provinsi Jawa Timur dengan luas areal seluas $1.159,50 \mathrm{~km}^{2}$. Kabupaten Jombang memiliki potensi dalam pengembangan usaha di bidang pertanian dengan jumlah lahan 49.476 ha. Kondisi luas panen dan jumlah produksi pertanian tanaman pangan dan hortikultura Kabupaten Jombang pada tahun 2015 dapat dilihat pada Tabel 4.1.

CV Tani Makmur didirikan oleh bapak Khamim. Pada awalnya bapak Khamim ini merupakan seorang petani yang menjual buah-buahan khususnya buah semangka sejak tahun 2002 di wilayah Megaluh dan Kabuh, Kabupaten Jombang. Hingga saat ini, beliau tetap menekuni bisnis buah semangka dengan sistem petani mitra.

\section{Analisis Lingkungan Perusahaan}

Analisis lingkungan merupa-kan salah satu proses yang harus dilakukan dalam manajemen strategis yang bertuju-an untuk mengidentifikasi faktorfaktor apa saja yang mempengaruhi peusaha-an. Pada umumnya lingkungan perusahaan terdiri dari lingkungan internal dan lingkungan eksternal.

Lingkungan internal merupa-kan proses pengidentifikasian terhadap faktorfaktor yang menjadi kekuatan dan kelemahan suatu perusahaan. Proses internal perusahaan tersebut dapat dianalisis dengan mengguna-kan pendekatan fungsional yaitu analisis yang dilakukan oleh masing-masing fungsi dalam perusahaan dengan mengkaji aspek sumberdaya manusia, pemasaran, keuangan/ akuntansi, produksi dan sistem informasi manajemen.

Petani mitra bisnis buah semangka CV Tani Makmur pada saat akan melakukan penanaman dilakukan survei lahan dan usulan lahan yang akan dijadikan tempat budidaya semangka, kemudian, dari pihak CV Tani Makmur, lahan yang diajukan tersebut di berikan keputusan. Kemudiaan setelah mendapat persetujuan lahan, CV Tani Makmur akan memberikan biaya sewa lahan dan biaya pembajakan lahan. Biaya sewa lahan per hektar mencapai Rp 2.000.000,-Biaya kebutuhan pupuk, benih, dan pestisida yang dibutuhkan selama kegiatan budidaya semangka serta pemeliharaan hingga panen secara keseluruhan ditanggung oleh pihak CV Tani Makmur. Petani mitra mengambil pupuk, benih, pestisida yang diberikan 
sebagai modal produksi dari CV Tani Makmur berdasarkan kebutuhan produksi per luas lahan. Biaya produksi buah semangka per hektar mencapai 20 juta rupiah. Pada saat panen buah semangka, petani mitra mencari pasar (konsumen agen buah) dan dapat juga menghubungi pihak CV Tani Makmur untuk memperoleh konsumen. Hasil panen yang diperoleh petani mitra kemudian digunakan untuk membayar jumlah kebutuhan input selama proses budidaya dilakukan kepada pihak CV Tani Makmur. Sedangkan kelebihan dari hasil panen sepenuhnya menjadi keuntungan petani mitra. Namun, jika hasil panen tidak mencukupi untuk membayar jumlah kebutuhan input produksi, maka petani mitra dituntut untuk melunasi pembayaran pada musim tanam selanjutnya. Untuk itu, petani mitra memiliki kesempatan yang tidak terbatas dalam melakukan kemitraan dengan pihak CV Tani Makmur untuk kegiatan budidaya buah semangka.

Tabel 4.2. Lokasi dan Luas Lahan Budidaya Semangka CV Tani Makmur Tahun 2017

\begin{tabular}{|l|l|c|}
\hline Kabupaten & Kecamatan & $\begin{array}{l}\text { Luas Lahan } \\
\text { (Ha) }\end{array}$ \\
\hline Jombang & Kabuh & 10 \\
\hline & Megaluh & 13 \\
\hline
\end{tabular}

Sumber : CV Tani Makmur (2017)

Agribisnis buah semangka CV Tani Makmur dalam penerapan sistem informasi manajemen telah menggunakan fasilitas seperti telepon, faksimail dan jaringan internet dalam kegiatan usahanya. Keberadaan fasilitas seperti telepon dan faksimail dapat digunakan dengan baik oleh karyawan sehingga terjalin komunikasi yang baik antar karyawan maupun terhadap para konsumen dan pemasok. Namun jaringan internet yang ada masih dimanfaatkan dengan baik berdasarkan hasil identifikasi faktor internal pada bisnis buah semangka CV Tani Makmur, dapat diperoleh beberapa faktor internal yang dapat mempengaruhi keberlangsungan bisnis buah semangka CV Tani Makmur. Faktor-faktor tersebut dapat dilihat pada Tabel 4.3.

Menurut Data Susenas (2011), terjadi peningkatan akan konsumsi buah-buahan sebesar 0,44 persen dari tahun 2010 hingga tahun 2011. Meskipun tidak merincikan data jenis buah yang mengalami peningkatan, namun secara umum hal ini menjadi peluang bagi perusahaan dalam membudidayakan buah khususnya buah semangka.

Kondisi ekonomi yang stabil mengarah pada pertumbuhan positif yang dapat mendukung kelancaran usaha di suatu daerah tertentu dan dapat mendorong tumbuhnya usaha-usaha baru. Pertumbuhan kearah positif ini terlihat dari mulai berkembangnya perusahaan industri buah segar di daerah Jombang yang kemudian CV Tani Makmur mengambil peluang pada produksi buah segar khususnya semangka di Kecamatan Megaluh dan Kabuh, Kabupaten Jombang.

\section{Kesimpulan}

Berdasarkan hasil dan pembahasan dari penelitian yang sudah dilakukan mengenai strategi pengembangan bisnis buah semangka pada CV. Tani Makmur dapat ditarik kesimpulan sebagai berikut:

1. Hasil analisis Matriks I-E, menempatkan bisnis buah semangka CV. Tani Makmur pada kuadran IV yakni perusahaan memiliki kemampuan internal kuat dan eksternal yang sedang. Strategi yang dapat dilakukan perusahaan adalah tumbuh dan membangun (grow and build) yang dapat dilakukan dengan melakukan strategi intensif seperti penetrasi pasar, pengembangan pasar, dan pengembangan produk, serta dapat dilakukan dengan strategi integratif seperti integrasi kedepan, integrasi kebelakang dan integrasi horizontal. Berdasarkan Matriks SWOT, dihasilkan strategi dimana prioritas pelaksanaan strategi tersebut diurutkan dari prioritas strategi utama yang dapat diutamakan untuk dijalankan lebih dahulu pada bisnis buah semangka CV. Tani Makmur dengan menggunakan perhitungan QSPM. Urutan prioritas strategi yaitu 1) mengembangkan kinerja SDM untuk meningkatkan produksi dan sasaran pasar yang lebih luas, 2) 
memberikan pelatihan dan pendidikan bagi karyawan, 3) melakukan kerjasama dengan petani semangka lainnya, 4) membeli lahan sendiri, 5) memanfaatkan potensi daerah serta dukungan pemerintah dan teknologi yang ada, 6) menetapkan kontrak perjanjian kepada pemasok dan pembeli dengan jelas, dan 7) menetapkan visi dan misi perusahaan.

2. Terdiri dari 2 identifikasi lingkungan, yaitu:

a) Faktor strategis internal yang dapat diidentifikasi pada bisnis buah semangka CV Tani Makmur meliputi kekuatan maupun kelemahan yang dimiliki. Adapun faktor strategis internal yang menjadi kekuatan dengan faktor mencakup pasar Jawa khususnya Jatim dan Jateng sebagai kekuatan utama bisnis buah semangka CV Tani Makmur. Sedangkan faktor strategis internal yang menjadi kelemahan dengan kegiatan promosi belum gencar merupakan kelemahan utama.

b) Faktor strategis eksternal yang dapat diidentifikasi meliputi peluang dan ancaman yang dihadapi dalam menjalankan bisnis buah semangka. Adapun faktor strategis eksternal yang menjadi peluang dimana adanya perdagangan ekspor impor menjadi peluang terbesar bisnis buah semangka CV Tani Makmur. Faktor strategis berupa ancaman sebanyak lima faktor dengan terjadinya perubahan iklim dan cuaca merupakan ancaman terbesar.

\section{Daftar Pustaka}

Ali Musa Pasaribu. 2012. Perencanaan dan Evaluasi Proyek Agribisnis Andi. Yogyakarta.

Arsyad dkk. dalam Sukarwati. 2011. Agribisnis, Teori dan Aplikasinya PT.Rajagravindo. Jakarta.

Beattie, B. R. And C. R. Taylor. 2010. Ekonomi Produksi. Penerbit Gajah Mada University Press, Yogyakarta
Saragih, Bungaran. 2012. Peranan Publik Relasion dan Pembangunan Pertanian.

Enrico Yaefullah, 2013. Agrobisnis Masalah Kualitas Buah untuk Eksport, http:// Ekonomi.kompasiana.com

Rangkuti, Frendy. 2010. Analisi SWOT, Teknik Membedah Kasus Bisnis, Cetakan Ke-9. PT Gramedia Pustaka Utama, Jakarta.

Hayat Yazid, 2013. Belajar Pertanian Organik, http://jurnalagrikulutur wordpress.com.

J. David Hunger dan Thomas L Whalen. 2010.Managemen Strategi. Andi, Yogyakarta.

Kasmir, 2012. Kewirausahaan, Edisi revisi, PT Raja Grafindo Persada, Jakarta

Makalah seminar, Istitut Pertanian Bogor.

Nuhung, I.A., 2007. Menbangun Pertanian Masa Depan. CV. Aneka IImu, Semarang.

Ali, Prabu. 2012. Kewirausahaan Berbasis Agribisnis, CV. Andi Offset. Yogyakarta.

Angelin C., Vivi. 2012. Strategi Pengembangan Bisnis Buah Semangka, CV. Salim Abadi, Lampung Tengah.

Freddy, Rangkuti. 2013. SWOT Balanced Scorecard (teknik Menyusun Strategi Korporat yang Efektif Plus Cara Mengelola Kinerja dan Resiko), PT Gramedia Pustaka Utama, Jakarta.

Salehudin, Moch. 2012. Karya Tulis IImiah, Bahan Pengajaran Pascasarjana Uniska. Kediri

Saragih, B. 2010. Membangun Sistem Agribisnis Suara dari Bogor. Yayasan USESE, Pustaka Wirausaha Muda. Edisi k-2. Bogor $206 \mathrm{hlm}$.

Sugiyono, 2010. Metode Penelitian Kuantitatif, Kualitatif dan $R \& D$, Cetakan ke-4 Alfabeta. Bandung

Adiyanto, Joko. 2011. Strategi Pengembangan Produksi Buah Naga Merah (Hylocereus Polyrhizus) Di Kabupaten Sukoharjo (Studi Kasus pada KUB "Pemuda Tani Sukoharjo"). Perpustakaan UNS. 
Faizah, Ekarini T.A. 2009. Analisis Pendapatan Usaha Tani Semangka (Citrullus Lanatus) Di Kabupaten Sragen. Perpustakaan UNS.
UNISKA.2017. Petunjuk Penulisan Usulan Penelitian Dan Tesis. Program studi Magister Manajemen Agribisnis. Pascasarjana Universitas Islam Kadiri. Kediri 